DOI: $10.29303 / \mathrm{jrpb} . v 9 \mathrm{i} 1.208$

ISSN 2301-8119, e-ISSN 2443-1354

Tersedia online di http://jrpb.unram.ac.id/

\title{
PERFORMANCE OF DRY HYDROPONIC SYSTEM ON CULTIVATION OF GREEN LETTUCE (Lactuca sativa L.)
}

\author{
Sugeng Triyono*), Roni Agung Laksono, Ahmad Tusi
}

University of Lampung, Faculty of Agriculture, Department of Agricultural Engineering, Jl. Sumantri Brojonegoro No1, 35145, Bandar Lampung, Lampung Province, Indonesia

Email $^{*}$ : striyono2001@yahoo.com

Accepted: December 2020

Approved: March 2021

\begin{abstract}
Dry hydroponic is an emerging system and gaining popularity among some hydroponic businesses, yet investigation on its performance has not been reported. Purpose of this research is to evaluate and compare performance of dry hydroponic system to floating and wick systems on green leafy lettuce cultivation. The experiment used Completely Randomized Design (CRD) with factorial arrangement. Two factors, hydroponic systems and aerator usages, were implemented. The hydroponic systems included Dry, Wick and Floating systems, while the use of aerator were with and without aerators. All treatment combinations consisted of 3 replicates. Parameters to be observed were nutrient solution parameters ( $\mathrm{pH}$, temperature, dissolved oxygen, water consumption), plant parameters (height, stem diameter, leaf width, number of leaves, leaf thickness, and canopy area, shoot fresh weight, water content, some chemical contents). Data sets were analyzed using analysis of variance followed by a least significant Difference (LSD) test at level of 5\%. Results showed that the interaction between the hydroponic system and the use of aerators were not significantly different for all parameters observed. The hydroponic systems were not significantly different too. The use of aerator was significant for the nutrient solution parameters ( $\mathrm{pH}$ and Dissolved Oxygen), water content, and phosphorus contents of leaves. In conclusion, Dry Hydroponic System has the same performances as compared to floating and wick systems.
\end{abstract}

Keywords: Aerator, dissolved oxygen, nutrient solution, static system, vegetables

\section{INTRODUCTION}

\section{Background}

Dry hydroponic system Cobden, (2021) is a term used to describe a variant of static hydroponic systems since this system uses standing nutrient solution. Unlike floating hydroponic system, the growing media in the dry system is not immersed in the nutrient solution so it is dry all the time.
At the beginning of planting, the dry system is similar to the floating system because the growing media is still immersed in nutrient solution and must be wet. After the roots have been growing and long enough, the nutrient solution water is lowered so the growing medium become dry because it is no longer immersed in nutrient solution. At the same time, the roots that are long enough hanging down into the nutrient solution so 
the plant can get water and nutrients. The existence of an air gap between the surface of the nutrient solution and the net pot support board (a floating board which is usually made of Styrofoam) allows the plant roots to get sufficient oxygen. The air gap also helps the nutrient solution cooling process so the temperature can be maintained stable. Dry growing media also make the plants cleaner because no moss grows on the media, under the plants, so the plants look clean and healthy.

Slightly different from dry hydroponics, floating hydroponic system is a static system characterized by the presence of standing nutrient solution (Sharma et al., 2018) but the growing media is always submerged in nutrient solutions. Because the support floats all the time, the floating system has no air gap between the floating board and the surface of the nutrient solution. In such environment, dissolved oxygen in nutrient solutions often drops to such a low level that it is often blamed for suboptimal plant growth. Lack of turbulence also causes the temperature of the nutrient solution tend to increase. In addition, Styrofoam floating board is an insulating material that can inhibit the heat dissipation process. In large scale businesses, floating systems are applied with various modifications such as aeration and recirculation of nutrient solutions so plant health can be maintained.

Wick hydroponic system is also another type of static system that does not have flowing nutrient solution (Gunawan et al., 2017). However, the wick system is more like between the two systems (floating system and dry system). There is an air gap between the water surface and the floating board too. The nutrient solution is delivered from the reservoir to the growing medium through the wick with a capillary manner. As a result, the growing medium is always wet and the roots of the plants can get water and nutrients from that wick. Since the wick hangs in the air (between the floating board and the nutrient solution), the roots also get more than enough oxygen from the air.
However, because it is always wet, the growing medium is always overgrown with moss so it looks dirty. In a large business scale, the wick system is unlikely to be adopted because it requires additional material, namely the wick, and of course it takes additional time to install.

The above explanation shows that the performance of the dry hydroponic system has been claimed to be better than the other two systems (floating and wick) in terms of efficiency of material usage, availability of oxygen, cleanliness of growing media, and plant health. However, research reports on the performance of dry hydroponic systems in scientific journals have not been found even though researches on hydroponics have been carried out long time ago, with many different purposes (Sharma et al., 2018). Hydroponic research reports available in scientific journals are mostly in continuous flow systems such as nutrient film technique (NFT) (Domingues et al., 2012) and deep flow technique (DFT) Both, (2021). The lack of available information regarding the performance of dry hydroponic systems indicates the need for research on the performance of dry hydroponic systems.

\section{Objective}

The purpose of this study was to examine and compare the performance of dry hydroponic systems to floating systems and wick systems on green lettuce cultivation (Lactuca sativa L. var Grand rapids). The use of green lettuce in this research is because green lettuce is widely cultivated hydroponically (USDA, 2011). In addition, lettuce is consumed in raw or for salad mixtures so the cleanliness and health of the vegetables is a priority aspect, making hydroponic cultivation of this vegetable very important.

\section{METHODOLOGY}

\section{Instrumentation and Materials}

Some instruments used in this study included seed trays, Styrofoam board, plastic nutrient solution container, net pots, 
aerators, hygrometers, $\mathrm{pH}$ and TDS meters, thermocouples, dissolved oxygen meters, rulers, calipers, micrometers, analytical scales, ovens, furnaces, cameras, and other lab equipment. The materials used in the study were green lettuce seeds, $\mathrm{AB}$ mix nutrients, rockwool, and flannel wick.

\section{Geographical Location}

This research was conducted from November 2018 - February 2019 in a greenhouse of the Water and Land Resources Engineering Laboratory of Agricultural Engineering Department and Soil Science Laboratory of Soil Science Department, Faculty of Agriculture, University of Lampung. Coordinates of the location lies on $5^{\circ} 22^{\prime} 26$ " south latitude, $105^{\circ} 14^{\prime} 58^{\prime \prime}$ east longitude, and altitude of $140 \mathrm{~m}$ above sea level. The maximum and minimum temperature and $\mathrm{RH}$ in the greenhouse and the ambience were recorded during the research implementation such as on Table 1.

Table 1. Average temperature and $\mathrm{RH}$ at the study site

\begin{tabular}{lrr}
\hline Atmosphere & Maximum & \multicolumn{1}{c}{ Minimum } \\
\hline Outside Greenhouse & & \\
Temp. $\left({ }^{\circ} \mathrm{C}\right)$ & $33,0 \pm 1,7$ & $24,8 \pm 2,1$ \\
RH $(\%)$ & $95,5 \pm 8,6$ & $68,9 \pm 12,6$ \\
Inside Greenhouse & & \\
Temp. $\left({ }^{\circ} \mathrm{C}\right)$ & $35,3 \pm 1,7$ & $25,4 \pm 2,2$ \\
RH (\%) & $95,7 \pm 10,0$ & $71,4 \pm 15,3$ \\
\hline
\end{tabular}

\section{Methods}

The completely randomized design (CRD) was used in factorial arrangement with two factors. Factor 1, the hydroponic system (S), consisted of three levels, namely Floating (F), Dry (D), and Wick (W). Factor 2 was the usage of aerator consisting of aerator (1) and non-aerator (0). Each treatment combination consisted of three replicates making a total of 18 experimental units. The data set was tested with analysis of variance and followed by using least significant difference test (LSD) at $\alpha=0.05$.

\section{Research Implementation}

The research implementation was divided into some stages, namely seedling, preparation of nutrient solutions, setup of hydroponic modules, planting and maintaining plants, and harvesting.

\section{Seedling}

Before sown, lettuce seeds obtained from the nearest agricultural shop were selected first by immersing them in water. Only good seeds (did not float) that were used, while bad seeds were not used. Two seeds of lettuce were inserted into the top part of rockwool medium $\left(2.3 \times 2.5 \times 3 \mathrm{~cm}^{3}\right)$, then the rockwool pieces were arranged on a seedling tray. The tray that has been filled with rockwool pieces was then saturated with water. After that, the seedlings were covered with paper and stored in a place that was not exposed to direct sunlight, over 24 hours. Most of the seeds had sprouted and started germinating. After the seeds germinated, the paper cover was opened and the seedling trays were moved and exposed to the direct sun light for about half a day. The seedlings were watered every day so that the moisture can be maintained for 21 days before being transferred to the net pots.

\section{Preparation of Nutrition Solutions}

At the same time, the nutrient packs of AB Mix (nutrient powder A and B), were dissolved in 2 separate bottles each using $500 \mathrm{~mL}$ of water. After stirring thoroughly, the two concentrated solutions A and B were stored as the stock solutions. When applied, the stock solutions were diluted with a ratio of about 1: 200 to become a ready-to-use solution. The ratio was adjusted gradually to make nutrient more concentrated as the plant getting matures.

\section{Setting of Hydroponic Module}

The hydroponic systems were made using 18 plastic containers of $11 \times 10 \times 15 \mathrm{~cm}^{3}$ (as nutrient reservoirs), each of which was surrounded or covered by $2 \mathrm{~cm}$ thick styrofoam. The top parts of which were styrofoam lid whose a hole for the net pot to 
sit on. For the floating system, the top cover floated on surface of the nutrient solution so the rockwool medium was always partially submerged in nutrient solution all the time. On the wick system, there was air gap between nutrient solution and the top cover. A flannel wick was used to deliver nutrient from the reservoir to the rockwool medium. In the dry system, there was air gap between nutrient solution surface and the top cover without a wick. Each system was made in two conditions, equipped with and without an aerator. Three small aerators (3 Watt each) were installed for this purpose. Each of the aerators served three nutrient solution containers, connected parallelly by using small silicon tube.

\section{Planting and Maintenance}

After 21 days, seedlings were selected and transferred from the seedling tray to the net pots. The pots of the seedlings were then placed on their respective nutrient reservoirs according to the predetermined treatment systems. Plant maintenance was carried out every day mainly to monitor and to maintain nutrient water levels. When the nutrient solution level dropped too low, the nutrient solution was added so that the surface raised to its initial level. Concentration of the nutrient solution was increased every week corresponding to the growth phase. Harvesting was done after the plants were 35 days after seedling.

\section{Parameters}

The nutrient solution parameters observed every day included: temperature (with thermocouple at 10.00 a.m.), electrical conductivity or EC (with EC meter), $\mathrm{pH}$ (with $\mathrm{pH}$ meter), dissolved oxygen or DO (with DO meter), evapotranspiration or ETc ( based on the changes of the nutrient solution depth measured with a ruler). The plant growth parameters observed were: height (with a ruler), number of leaves, leaf thickness (with micrometers), stem diameter (with calipers), and canopy area (with a ratio of weight to area). The canopy area was measured by taking photograph from above (nadir view), then calculated by weight comparisons. Yield parameters at harvest consisted of: fresh weight, moisture content (gravimetric method), ash content (gravimetric and combustion method), NPK contents (standard analysis methods)

\section{RESULTS AND DISCUSSION}

\section{Nutrient Solution}

Analysis of variance showed that the interaction between hydroponic system treatment and the use of aeration was not significant at the level of $\alpha=0.05$ for all parameters of the nutrient solution $(\mathrm{pH}$, temperature, dissolved oxygen, ETc). The effect of the hydroponic systems on all parameters was not significantly different either. The effect of aeration was not significant for temperature and ETc parameters, but significant for $\mathrm{pH}$ and dissolved oxygen. Table 2 presents averages of $\mathrm{pH}$, temperatures, D.O, and cumulative ETc from the beginning of planting date to harvest time,

Table 2. Effect of hydroponic and aeration systems on nutrient solution parameters

\begin{tabular}{lcccc}
\hline \multicolumn{1}{c}{ Treatments } & $\mathrm{pH}$ & Temperature $\left({ }^{\circ} \mathrm{C}\right)$ & DO $(\%)$ & ETc $(\mathrm{mm})$ \\
\hline Hydroponic Systems & & & & \\
$\quad$ Floating (F) & $6,77 \pm 0,10$ & $30,06 \pm 0,11$ & $60,45 \pm 23,51$ & $164,17 \pm 37,71$ \\
Dry (D) & $6,85 \pm 0,41$ & $30,19 \pm 0,17$ & $63,16 \pm 37,52$ & $187,50 \pm 36,53$ \\
Wick (W) & $6,76 \pm 0,25$ & $30,46 \pm 0,26$ & $60,56 \pm 36,75$ & $182,08 \pm 19,45$ \\
Aeration Systems & & & & \\
$\quad$ Aeration (1) & $7,38 \pm 0,05^{\mathrm{a}}$ & $30,12 \pm 0,20$ & $93,88 \pm 0,38^{\mathrm{a}}$ & $200,00 \pm 11,81$ \\
$\quad$ Non Aeration (0) & $6,21 \pm 0,07^{\mathrm{b}}$ & $30,25 \pm 0,27$ & $28,91 \pm 2,76^{\mathrm{b}}$ & $155,83 \pm 16,22$ \\
\hline
\end{tabular}

*) Means with the different letters are significantly different at $\alpha=0.05$ 
Among the hydroponic and the aeration systems, $\mathrm{pH}$ ranged from $6,21 \pm 0,27$ to $6,85 \pm 0,41$. According to Singh et al. (2019), the optimum $\mathrm{pH}$ for hydroponic vegetables was around 5,5 to 6,5 (Table 2). So, the non-aeration system was the only system that had the optimum $\mathrm{pH}$ value since its $\mathrm{pH}$ was $6,21 \pm 0,07$. The value of $\mathrm{pH}$ represents a measure of acidity or hydrogen ion concentration in the nutrient solution. Changes of $\mathrm{pH}$ in nutrient solution were primarily due to an uneven uptake of anions and cations (Frick \& Mitchell, 1993). In this study, hydroponic systems did not affect $\mathrm{pH}$ alteration since they were not significant. But the use of aeration did elevate $\mathrm{pH}$, and the $\mathrm{pH}$ value in the aeration system was significantly higher than that in the non- aeration system. The same result is also reported by Bodenmiller (2017). Precipitation of calcium when reacts with phosphate and released $\mathrm{OH}^{-}$can be associated with this phenomenon. Calcium and phosphate exist in the nutrient solution, and their reaction are accelerated by turbulences of air bubbles. The profile of $\mathrm{pH}$ for six treatment combinations during planting season is presented in Figure 1. The $\mathrm{pH}$ values of the nutrient solution in the nonaerated systems appeared to be consistently lower than the $\mathrm{pH}$ values of the nutrient solution in the aeration system, from the beginning of planting to the harvest time. At this point, dry hydroponic had no different performance from the other two systems.

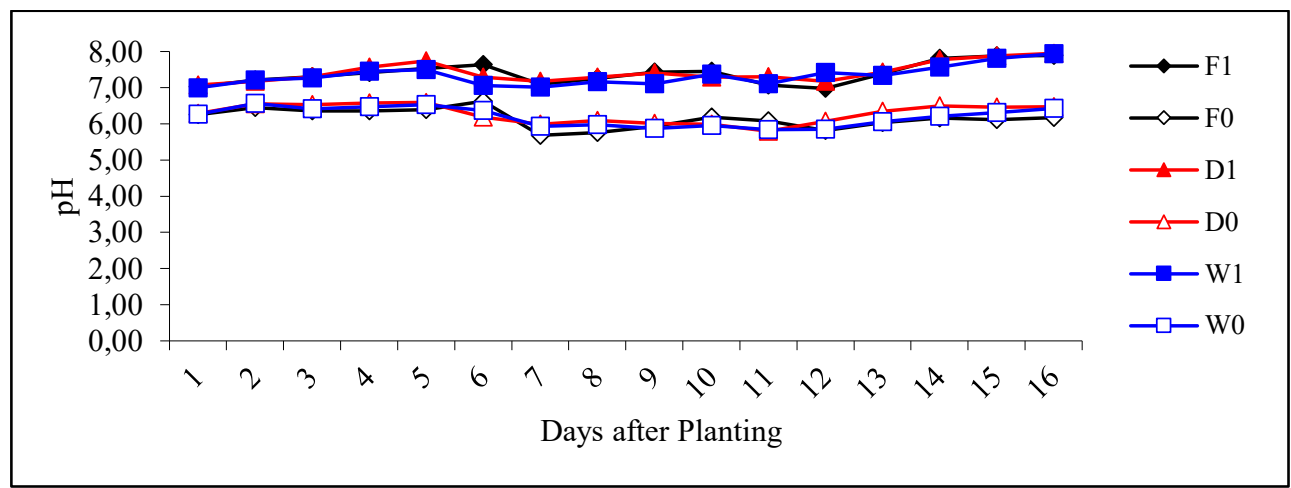

Figure 1. The $\mathrm{pH}$ profile of the nutrient solution during lettuce growth

The temperatures of the nutrient solution in the hydroponic and aeration systems were not significant as mentioned before. Among the hydroponic and aeration systems, the nutrient temperatures ranged from $30,06 \pm 0,11^{\circ} \mathrm{C}$ to $30,46 \pm 0,26^{\circ} \mathrm{C}$ with an average of $30.24 \pm 0.25^{\circ} \mathrm{C}$ (Table 2). In theory, the temperature of non-aerated nutrient solution could accumulate and increase especially on the day light. Meanwhile, the turbulence due to the aeration bubbles of the nutrient solution can help the cooling process. However, the data showed that the temperatures of the nutrient solution in all the treatments were not significant. This condition may be interpreted that the effect of the insulating material (Styrofoam) which covered the surround and the top parts of the nutrient containers was quite effective, making temperatures of all nutrient solutions were not significantly different. The temperature profiles for six treatment combinations mostly coincided all the time from the beginning of planting to the harvest date (Figure 2). Based on the nutrient temperatures, performances of the three hydroponic systems were not different either. 


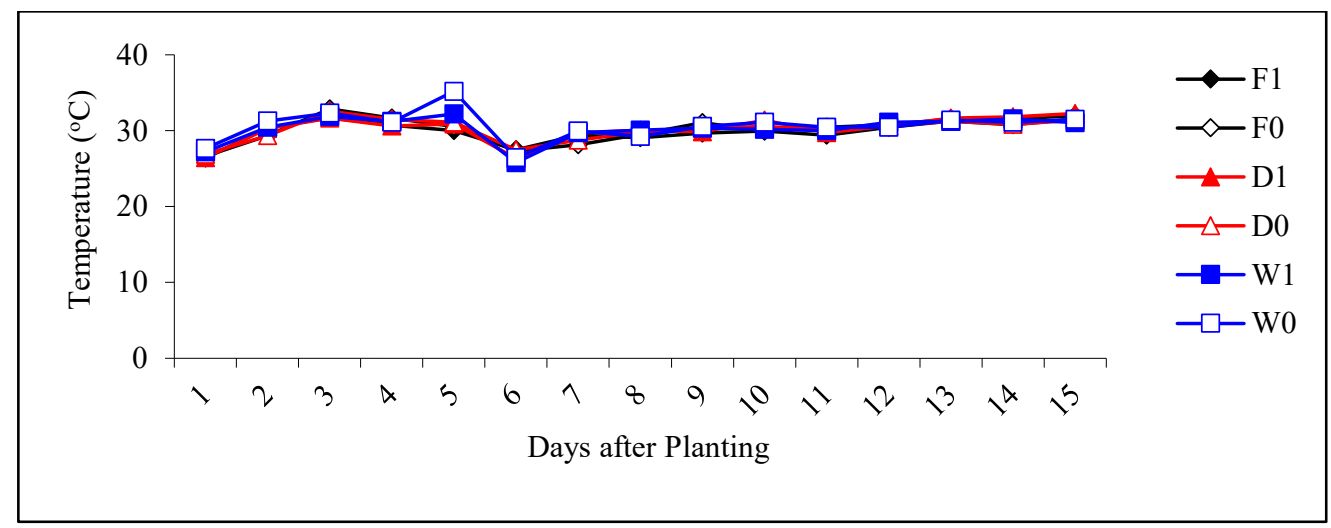

Figure 2. Temperature profile of the nutrient solution during lettuce growth

For the parameter of dissolved oxygen (DO), the effect of hydroponic system was not significant but the effect of aeration was significant. The average of $\mathrm{DO}$ in the aeration systems was $93.88 \pm 0.38 \%$ and the dissolved oxygen in the non-aeration system was $28.91 \pm 2.76 \%$ (Table 2 ). This result indicated that the use of aerator was very effective to increase DO in the nutrient solution. Dissolved oxygen in the nonaeration system was $28.91 \pm 2.76 \%$ (roughly equivalent to a concentration of $2.3 \mathrm{mg} / \mathrm{L}$ ) which could be categorized as very low and close to anoxic environment. The DO of 2.3 $\mathrm{mg} / \mathrm{L}$ was very low if compared to river's
DO which is normally more than $4 \mathrm{mg} / \mathrm{L}$ (USGS, 2006). The very low DO probably could be addressed mainly to plant's roots absorption. Regardless of very high $\mathrm{pH}$ in the aerated nutrient solution (as mentioned before), aeration succeeded to increase nutrient solution DO. But for the three different hydroponic systems (dry, floating, and wick), there were no difference in DO changes. The profile of DO in nutrient solutions during plant growth is presented in Figure 3. Dissolved oxygens in the nonaerated systems were consistently lower all the time.

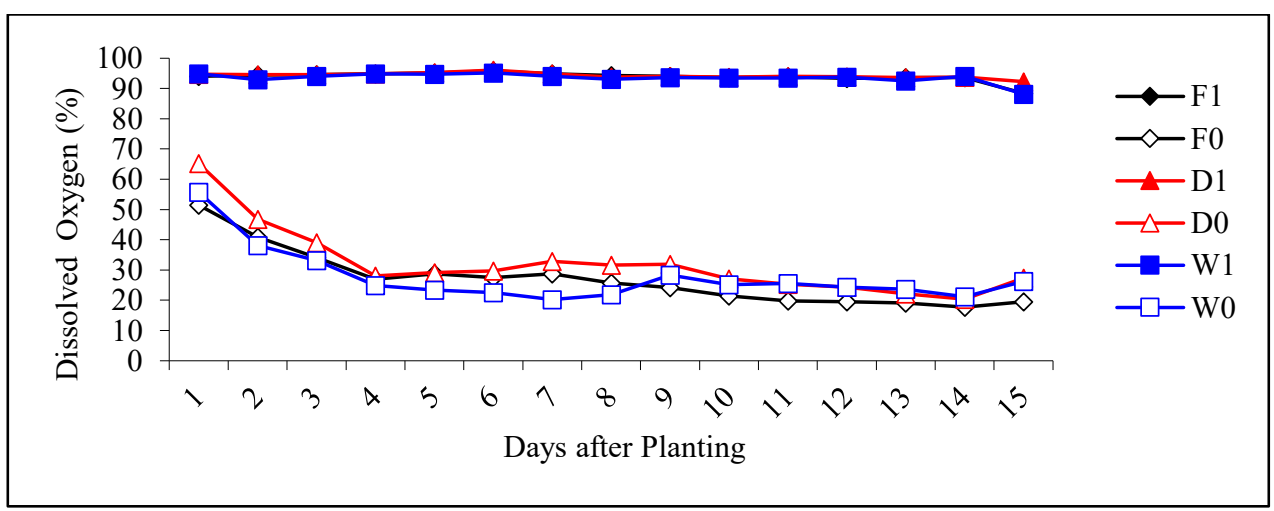

Figure 3. The oxygen profile of the nutrient solution during lettuce growth

For the cumulative evapotranspiration (ETc), analysis of variance showed that the effects of hydroponic system and the aeration system were not significant. The cumulative ETc during planting season ranged from $155.83 \pm 16.22 \mathrm{~mm}$ to $200 \pm$ $11.81 \mathrm{~mm}$, with the average of $177.9 \pm 24.35$ $\mathrm{mm}$ (Table 2). The aeration which produced turbulence of nutrient solution theoretically increased direct evaporation. One issue that could be used to explain the phenomenon was probably transpiration from the plant leaves occupies a much larger portion than the direct evaporation portion from the surface of nutrient solution. The effect of turbulence of the nutrient solution was probably not very much. Considering that lettuce is very fast growing vegetable in very 
short growing cycle, it is realistic to predict that water consumption through transpiration is very huge as compared to direct evaporation. However, this hypothesis needs to be tested at other research opportunities. Figure 4 shows cumulative evapotranspiration profile of six treatment combinations of lettuce during the growth. Although not significant, the evapotranspiration lines of aerated systems were always higher all the time. Again, the three hydroponic systems did not show different performances based on evapotranspiration parameter.

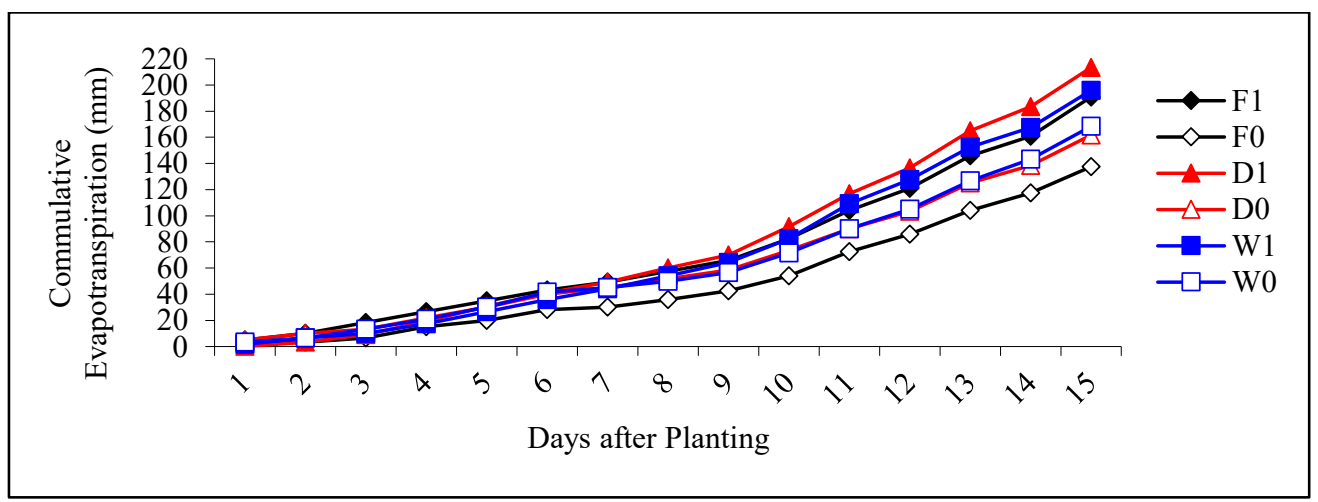

Figure 4. Cumulative evapotranspiration profile

\section{Plant Growth}

Analysis of variance showed that the effects of hydroponic systems and aeration systems on growth and yield of green lettuce were not significant except for water content
$\left(\mathrm{W}_{\mathrm{C}}\right)$. Plant growth and yield data (height, stem diameter, leaf width, number of leaves, canopy area, shoot fresh weight, moisture content) are presented in Table 3.

Table 3. Harvest data of green lettuce

\begin{tabular}{lcccccccc}
\hline \multicolumn{1}{c}{ Treatments } & $\begin{array}{c}\text { height } \\
(\mathrm{cm})\end{array}$ & $\begin{array}{c}\text { stem } \\
\text { diameter } \\
(\mathrm{cm})\end{array}$ & $\begin{array}{c}\text { leaf } \\
\text { width } \\
(\mathrm{cm})\end{array}$ & $\begin{array}{c}\text { number } \\
\text { of leaves }\end{array}$ & $\begin{array}{c}\text { Leaf } \\
\text { thickness } \\
(\mathrm{mm})\end{array}$ & $\begin{array}{c}\text { canopy } \\
\text { area } \\
\left(\mathrm{cm}^{2}\right)\end{array}$ & $\begin{array}{c}\text { Shoot } \\
\text { fresh } \\
\text { weight } \\
(\mathrm{g})\end{array}$ & $\begin{array}{c}\mathrm{W}_{\mathrm{C}} \\
(\%)\end{array}$ \\
\hline hydroponic systems & & & & & & & & \\
$\quad$ Floating (F) & 24,92 & 1,68 & 18,83 & 16,83 & 0,54 & 1686,68 & 122,00 & 92,40 \\
Dry (D) & 24,75 & 1,62 & 19,00 & 19,50 & 0,38 & 1922,09 & 135,00 & 93,01 \\
$\quad$ Wick (W) & 24,50 & 1,62 & 19,92 & 19,00 & 0,60 & 2076,02 & 144,33 & 93,83 \\
Aeration systems & & & & & & & & \\
Aeration (1) & 25,28 & 1,68 & 19,83 & 19,00 & 0,56 & 2078,42 & 158,33 & $93,75^{\text {a }}$ \\
Non Aeration (0) & 24,17 & 1,59 & 18,67 & 17,89 & 0,45 & 1711,44 & 109,22 & $92,41^{\text {b }}$ \\
\hline
\end{tabular}

*) Means with the different letters are significantly different at $\alpha=0.05$

At the harvest time, the height of lettuce ranged from $24.17-25.28 \mathrm{~cm}$, stem diameter ranged from $1.59-1.68 \mathrm{~cm}$, leaf width ranged from $18.33-19.83 \mathrm{~cm}$, number of leaves ranged from 16.83 - 19.50, leaf thickness ranged from $0.38-0,60 \mathrm{~mm}$, canopy area ranged from $1486.68-2078.42$ $\mathrm{cm}^{2}$, and shoot fresh weight ranged from 109.22 - 158.33 g. Although there were variations, these differences were not statistically significant based on either the hydroponic system nor aeration systems.

In other words, the hydroponic systems of floating, dry, and wick systems showed no significant difference in performances. Although they performed with no difference, dry system may be better based on other reasons. In dry system, the 
rockwool medium was cleaner (not mossy) and dry so the plants are also cleaner. These were contrast to the floating system the medium of which was always wet, mossy, and dirt looking. In addition, dry system does not require additional material such as a wick in the wick system either.

The use of aeration systems among the three different systems (floating, dry, wick) was no difference in the performance because the growth and yield of lettuce were not better to each other. The only parameter that shows a difference in performance between aerated and non-aerated systems was the moisture content of lettuce leaves. The water content data mentioned above (Table 3 ) the water content of plants with an aeration was $93.75 \%$, which is significantly higher than that of plants with a nonaeration, namely $92.41 \%$. The higher water content of the plant could be a part of the answer why water consumption was higher in the aeration system. However, this did not provide an advantage from consumer side because high water content of lettuces actually reduces the quality of the plants in term of nutrient content. The same result is also reported by (Bodenmiller, 2017) as dry weight of lettuce in non-aeration system was $12 \%$ higher (meaning lower water content) than dry weight of lettuce in the aeration system. At last, the conclusion that can be drawn is that the use of aeration is inefficient (adding costs) but ineffective for the growth and yield addition of green lettuce, in this experiment. Furthermore, as mentioned before, aeration tended to increase $\mathrm{pH}$ to above the optimum ranges.

At the discussion of the dissolved oxygen section above, the aeration and nonaeration systems showed significant differences of DO. However, evidently the high difference of DO did not make a difference to the growth and yield of green lettuce. Goto et al. (1996) reported the same results, that DO between $25-200 \%$ (of saturation) had no significant effect on yields of green lettuce, although this finding was contrast to the results reported by (Krisnawati, 2015) and (Krisna et al., 2017).
This was presumably because plant roots mainly obtained oxygen from the air directly (above the nutrient solution), not just from dissolved oxygen in the nutrient solution. For floating systems, many roots grow in rockwool media which is always wet but not completely immersed in nutrient solution making the roots may get oxygen directly from the air. For the wick system, the roots grow well in the wet rockwool and the wet wicks, so the roots eventually get oxygen directly from the air. For dry systems, the dangling roots grow well in the air gap between the dry rockwool medium and the surface of the nutrient solution so they get significant oxygen directly from the air gap. These situations might be the reason why different dissolved oxygen in the nutrient solutions did not make any differences in the plant growths and yields.

However, what should be noted is that the assumptions above may be different from the facts of the true mechanism, and other factors might control the mechanism. Goto et al. (1996) stated that lettuce is a type of plant that is not sensitive to dissolved oxygen. So, plant varieties determine the sensitivity to dissolved oxygen. Bodenmiller (2017) found the opposite result, where lettuce in a non-aerated floating aquaculture system (control) produced $29 \%$ higher yields as compared to that in aeration system. Meanwhile, Roosta et al. (2016) found that the optimum growth of eggplant plants in the floating system occurred at a dissolved oxygen concentration of $4 \mathrm{mg} / \mathrm{L}$ (far below the saturation). Ningrum et al. (2014) obtained that intermittent aeration (15 minutes on and 60 minutes off) is the optimum aeration system for mustard greens. At last, the three hydroponic systems tested did not have different performances in growths and yields of green lettuce.

\section{Some Chemical Contents}

Nitrogen, phosphorus, and potassium Uptakes in lettuce leaves were measured as a representation of the quality of the green lettuce as effected by the treatment 
combination between the hydroponic systems and the aeration systems. Analysis of variance showed that the phosphorus level was the only significant parameter affected by the aeration system (Table 4 ).

Table 4. Effect of hydroponic system and aeration on nitrogen, phosphorus, and potassium levels in green lettuce

\begin{tabular}{llll}
\hline $\begin{array}{c}\text { Treatment } \\
\text { Combinations }\end{array}$ & $\mathrm{N}(\%)$ & $\mathrm{P}(\%)$ & $\mathrm{K}(\%)$ \\
\hline hydroponic systems & & & \\
Floating (F) & 3,68 & 0,14 & 2,85 \\
Dry (D) & 3,44 & 0,13 & 2,94 \\
Wick (W) & 3,79 & 0,14 & 3,84 \\
Aeration systems & & & \\
Aeration (1) & 3,56 & $0,13^{\mathrm{b}}$ & 2,84 \\
$\quad$ Non Aeration (0) & 3,71 & $0,15^{\mathrm{a}}$ & 3,04 \\
\hline
\end{tabular}

*) Means with the different letters are significantly different at $\alpha=0.05$

Nutrient concentrations in lettuce biomass among the treatments ranged from $3.44-3.79 \%$ for nitrogen, $0.13-0.15 \%$ for phosphorus and $2.85-3.84 \%$ for potassium. Many factors influenced nutrient uptake in lettuce, such as: location and season (Singer et al., 2015), temperature (Thompson et al., 1998), cultivar (Lastra et al., 2009), and nutrition (Kleiber et al., 2013); Vojnich et al., 2016). The fact that nitrogen and potassium uptake was not significantly different was in line with other growth parameters and harvest weight. However, the data showed that phosphorus uptake was significantly affected by aeration system. The data showed that the phosphorus uptake in the non aeration system was higher than that in the aeration system. Phosphate is very reactive with with calcium to form settleable calcium phosphate. When the nutrient solution gets aerated, air bubbles from the aerator stone created turbulence and was likely to facilitate the reaction between calcium and phosphate to form settleable calcium phosphate which was not available to plant roots. This mineral deposition symptom is also noted by Roosta et al. (2016) when nutrient solution is aerated. However, this result is different from that reported by Krisna et al. (2017) as calcium absorption in lettuce is higher in an aerated floating system than in non-aerated system. These differences suggested that there is still a room for further research and discussion. Finally, the floating, dry, and wick systems did not show any different performances in terms of nutrient uptake, and the aeration even lessened the phosphorus uptake.

\section{CONCLUSIONS AND SUGGESTIONS}

\section{Conclusions}

Conclusion that can be obtained from the results and discussion was that Dry Hydroponics System performed no difference from Floating System and Wick System for green lettuce cultivation. In addition, the use of aerators increased dissolved oxygen concentration and $\mathrm{pH}$ significantly but was not significant for the lettuce growth and yield, and even lessened phosphorus uptake.

\section{Suggestions}

Research on the partition of the evaporation and transpiration processes needs to be carried out because in this study evaporation was not significantly affected by aeration. Whereas; theoriticaly, evapotranspiration is supposed to be affected by turbulence and air bubbles of the aerator.

\section{Acknowledgments}

High appreciation is delivered to the Faculty of Agriculture and the University of Lampung which provided financial support for the implementation of this research project.

\section{REFERENCES}

\section{Bodenmiller, D. (2017). Effects of aeration on lettuce (Lactuca sativa) growth in deep water culture aquaponics [Bachelor's thesis|]. Tampereen ammattikorkeakoulu. http://www.theseus.fi/handle/10024/1 39274}


Both, A. J. (2021). Ten years of hydroponic lettuce research. https://aesop.rutgers.edu

Cobden, J. (2021). Dry Hydroponics for Short Cycle Crops. AIS Greenworks. Retrieved January 24, 2021, from https://www.aisgreenworks.com.au/dr y-hydroponics/

Domingues, D. S., Takahashi, H. W., Camara, C. A. P., \& Nixdorf, S. L. (2012). Automated system developed to control $\mathrm{pH}$ and concentration of nutrient solution evaluated in hydroponic lettuce production. Computers and Electronics in Agriculture, 84, 53-61.

Frick, J., \& Mitchell, C. (1993). Stabilization of $\mathrm{pH}$ in Solid-matrix Hydroponic Systems. HortScience: A Publication of the American Society for Horticultural Science, 28, 981-984.

Goto, E., Both, A. J., Albright, L. D., Langhans, R. W., \& Leed, A. R. (1996). Effect of Dissolved Oxygen Concentration on Lettuce Growth in Floating Hydroponics. Acta Horticulturae, 440, 205-210.

Gunawan, I., Asbur, Y., \& Rambe, D. H. (2017). Agronomic Characteristics of Mustard (Brassica juncea L.) on the Application of Fertilizer Solution and Flannel Size at Wick Hydroponic System. International Journal of Science and Research Methodology 6(3), 65-78.

Kleiber, T., Starzyk, J., \& Bosiacki, M. (2013). Effect of nutrient solution, effective microorganisms (EM-A), and assimilation illumination of plants on the induction of the growth of lettuce (Lactuca sativa L.) in hydroponic cultivation. Acta Agrobotanica, 66(1), 27-38.
Krisna, B., Putra, E. E. T. S., Rogomulyo, R., \& Kastono, D. (2017). Pengaruh Pengayaan Oksigen dan Kalsium terhadap Pertumbuhan Akar dan Hasil Selada Keriting ( Lactuca sativa L.) pada Hidroponik Rakit Apung. Vegetalika, 6(4), 14-27.

Krisnawati, D. (2015). The Effect of Aeration on Baby Kailan (Brassica Oleraceae Var. Achepala) Growth in Floating System of Hydroponic Technology inside and outside the Greenhouse. Jurnal Teknik Pertanian Lampung (Journal of Agricultural Engineering), 3(3), 213-222.

Lastra, O., Tapia, M. L., Razeto, B., \& Rojas, M. (2009). Response of Hydroponic Lettuce Cultivars to Different Treatments of Nitrogen: Growth and Foliar Nitrate Content. Idesia (Arica), 27(1).

Ningrum, D. Y., Triyono, S., \& Tusi, A. (2014). Pengaruh Lama Aerasi Terhadap Pertumbuhan Dan Hasil Tanaman Sawi (Brassica juncea L.) pada Hidroponik DFT (Deep Flow Technique). Jurnal Teknik Pertanian Lampung (Journal of Agricultural Engineering), 3(1), 83-90.

Roosta, H. R., Bagheri, M. H., Hamidpour, M., \& Roozban, M. R. (2016). Interactive Effects of Nitrogen Form and Oxygen Concentration on Growth and Nutritional Status of Eggplant in Hydroponics. Journal of Agricultural Science and Technology, 18(3), 731739.

Sharma, N., Acharya, S., Kumar, K., Singh, N., \& Chaurasia, O. P. (2018). Hydroponics as an advanced technique for vegetable production: An overview. Journal of Soil and Water Conservation, 17(4), 364-371.

Singer, S. M., Hamza, A. E., El-Samad, E. H. A., Sawan, O. M., El-Behairy, U. 
A., \& Abou-Hadid, A. F. (2015). Growth, yield and mineral contents of lettuce cultivars grown in nutrient film technique (NFT) at different transplanting dates. Research Journal of Pharmaceutical, Biological and Chemical Sciences, 6(1), 172-183.

Singh, H., Dunn, B., \& Payton, M. (2019). Hydroponic $\mathrm{pH}$ Modifiers affect Plant Growth and Nutrient Content in Leafy Greens. Journal of Horticultural Research, 27(1), 31-36.

Thompson, H. C., Langhans, R. W., Both, A.-J., \& Albright, L. D. (1998). Shoot and Root Temperature Effects on Lettuce Growth in a Floating Hydroponic System. Journal of the
American Society for Horticultural Science, 123(3), 361-364.

USDA. (2011). U.S. Lettuce Statistics. Retrieved January 24, 202. https://usda.library.cornell.edu/concer $\mathrm{n} /$ publications/cc08hf60z

USGS. (2006). Chapter A6. Section 6.2. Dissolved oxygen. Retrieved January 24, 2021. https://doi.org/10.3133/twri09A6.2

Vojnich, V. J., Hüvely, A., Pető, J., \& Novák, D. I. (2016). Nutrient content in leaves of hydroponic lettuce (Lactuca sativa convar. Capitata L.) on higher magnesium and nitrogen nutrient treatment. Acta Biologica Szegediensis, 60(2), 167-169. 